NASA Technical Memorandum 89859

\title{
Rapid Thermal Annealing of Amorphous Hydrogenated Carbon (a-C:H) Films
}

Samuel A. Alterovitz, John J. Pouch, and Joseph D. Warner Lewis Research Center Cleveland, Ohio

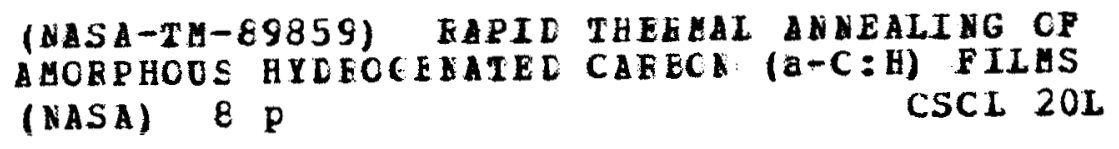
$\triangle M O R P H O O S$ H
(MASA) 8 p

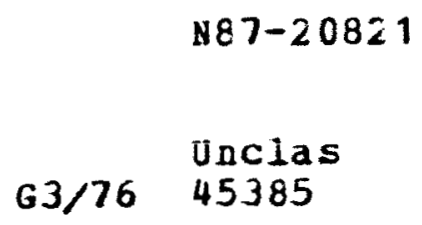

Prepared for the 1987 Spring Meeting of the Materials Research Society Anaheim, California, April 21-25, 1987 
RAPID THERMAL ANNEALING OF AMORPHOUS HYDROGENATED CARBON (a-C:H) FILMS

SAMUEL A. ALTEROVITZ, JOHN J. POUCH, AND JOSEPH D. WARNER National Aeronautics and Space Administration, Lewis Research Center, Cleveland, Ohio 44135

\section{ABSTRACT}

Amorphous hydrogenated carbon (a-C:H) films were deposited on silicon and quartz substrates by a $30 \mathrm{kHz}$ plasma discharge technique using methane. Rapid thermal processing of the films was accomplished in nitrogen gas using tungsten halogen light. The rapid thermal processing was done at several fixed temperatures (up to $600{ }^{\circ} \mathrm{C}$ ), as a function of time (up to $1800 \mathrm{sec}$ ). The films were characterized by optical absorption and by ellipsometry in the near UV and the visible. The bandgap, estimated from extrapolation of the linear part of a Tauc plot, decreases both with the annealing temperature and the annealing time, with the temperature dependence being the dominating factor. The density of states parameter increases up to 25 percent and the refractive index changes up to 20 percent with temperature increase. Possible explanations of the mechanisms involved in these processes are discussed.

\section{INTRODUCTION}

Rapid thermal processing is an emerging technology. It has several applications in electronic materials $[1,2]$ mostly at relatively high temperatures $\left(>700^{\circ} \mathrm{C}\right)$. However, in many cases, processing at temperatures below $600{ }^{\circ} \mathrm{C}$ for times of $20 \mathrm{sec}$ or lower are adequate. Some examples of the latter are: ohmic contacts on III- $V$ compound semiconductors [3], improving metalization properties on Si [4] or reduction of trapping in a $\mathrm{SiO}_{2}$ insulating film [5].

In this study we will present the effects of rapid thermal processing at moderate temperatures $\left(<600^{\circ} \mathrm{C}\right)$ on amorphous hydrogenated carbon $(\mathrm{a}-\mathrm{C}: \mathrm{H})$ films. This is, to our knowledge, the first report of a study of the effects of a combination of time and temperature on the properties of $a-C: H$ films. Most of the characterization has been done using optical absorption in the visible. In addition, thermal annealing effects obtained for short processing time $(20 \mathrm{sec})$ have been studied by ellipsometry. This work will provide much needed information for applications of $a-C: H$ fllms where rapid thermal processing may be required. One such application is in III-V semiconducting electronic materials, where a-C:H films show promising results $[6,7]$.

\section{EXPERIMENTAL}

Samples were prepared on quartz and Si substrates using a $30 \mathrm{kHz}$ plasma deposition unit. Measurements of the film properties were done using a UV-Vis spectrometer and a rotating analyzer ellipsometer. Detalls of the preparation and characterization techniques were reported elsewhere [8] and will not be repeated here. The only change in the characterization technique was the use of a $X_{e}$ lamp as light source for the ellipsometer, instead of the Hg lamp. We used a 4200 cut off filter to eliminate high energy stray light for measurements above this wavelength.

The rapid heating module [9] has a rectangular quartz chamber, 5 in. wide, $8.5 \mathrm{in}$. long, and $1 \mathrm{in}$. high. It is heated by a microprocessor controlled bank of $1.5 \mathrm{~kW}$ tungsten halogen lamps, with seven lamps on top and 
six on the bottom. Two mass flow controllers were used to control the processing gas. We used dry nitrogen gas with flow rates of order two liter/ minute. The sample holder is a 3 in. quartz ring on which we placed a si wafer. To enhance light absorption, the Si wafer was coated with $200 \AA \mathrm{Ta}$ followed by 3000 \& Au. The sample was placed on top of the Si wafer, touching the metallic coating. The temperature was measured by a type $k$ thermocouple in contact with the bottom of the si wafer. There is at least one-half inch of contact between the two. A typical $600{ }^{\circ} \mathrm{C}$ heating cycle is shown in Fig. 1. We have carefully avoided temperature overshoot. The heating rate was of order $40{ }^{\circ} \mathrm{C} / \mathrm{sec}$ for $600{ }^{\circ} \mathrm{C}$ processing, with lower values for lower temperatures. For long processing times ( 1 min. or more), temperature oscillations of order $\pm 5{ }^{\circ} \mathrm{C}$ were observed. Samples were processed with both the film pointing upward and downward. The heating current used for processing quartz or Si substrates were different, as the quartz plate has much more heat capacity than the si substrate.

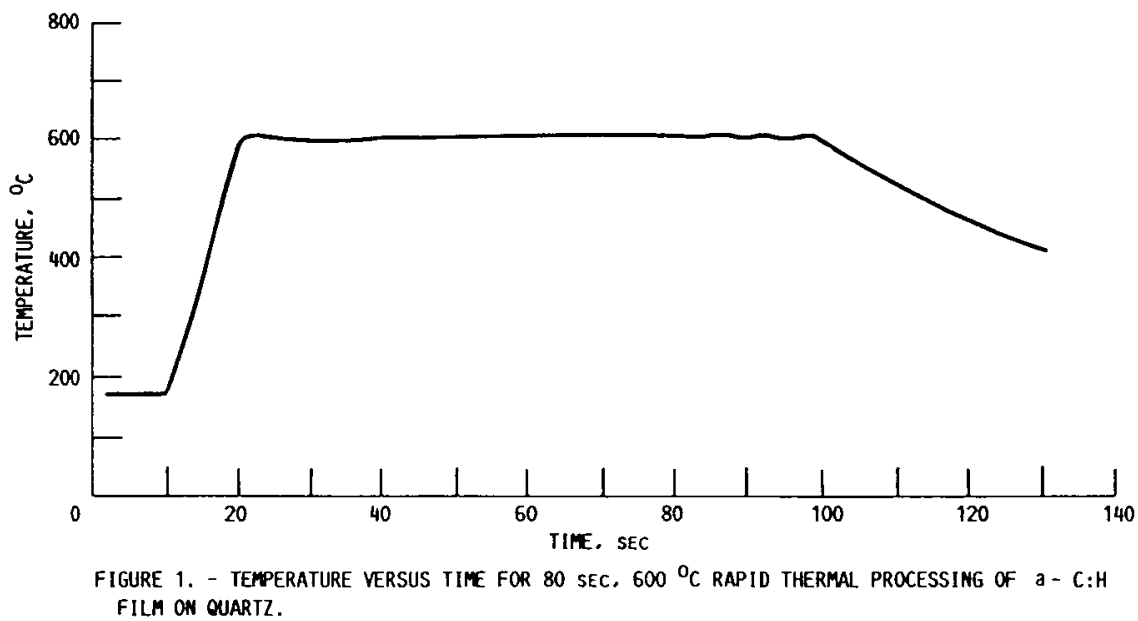

RESULTS

The samples used in this study were prepared in two deposition runs. Both runs were nominally equal, using $150 \mathrm{~W}, 70 \mathrm{sccm}$ flow rate methane plasma (corresponding to $315 \mathrm{~mm}$ ). Absorption in the UV-Visible range was measured on quartz substrates. Absorbance versus wavelength for samples processed 20 and $160 \mathrm{sec}$ and the reference, are shown in $\mathrm{Fig}, 2$. The optical bandgap $E_{0}$ was found [10] using a Tauc plot, i.e. (AE) $1 / 2$ versus $E$, where $E$ is the energy. For amorphous materials, this plot is expected to be linear. A typical plot is shown in Fig. 3. We can see that the linearity range of (AE) $1 / 2$ versus $E$ is markedly reduced with the therma 1 processing. However, the slight difference in absorption observed in Fig. 2 between the samples heated for 20 and $160 \mathrm{sec}$, is now quantitatively described by a change in the optical bandgap $E_{0}$. We kept the fitting range of $(A E)^{1 / 2}$ versus $E$ the same for all isothermal runs. This procedure gave us both consistency in comparing results for different samples and the best least square fits to linear dependency. The optical bandgaps of the quartz substrate reference samples made in the two deposition runs were 2.4 and $2.6 \mathrm{eV}$. Results of the optical bandgap on quartz substrates versus the processing time are shown in Figs. $4(a)$ and $4(b)$. There is a slight decrease of $E_{0}$ at longer processing times, especially for the $400{ }^{\circ} \mathrm{C}$ runs. 


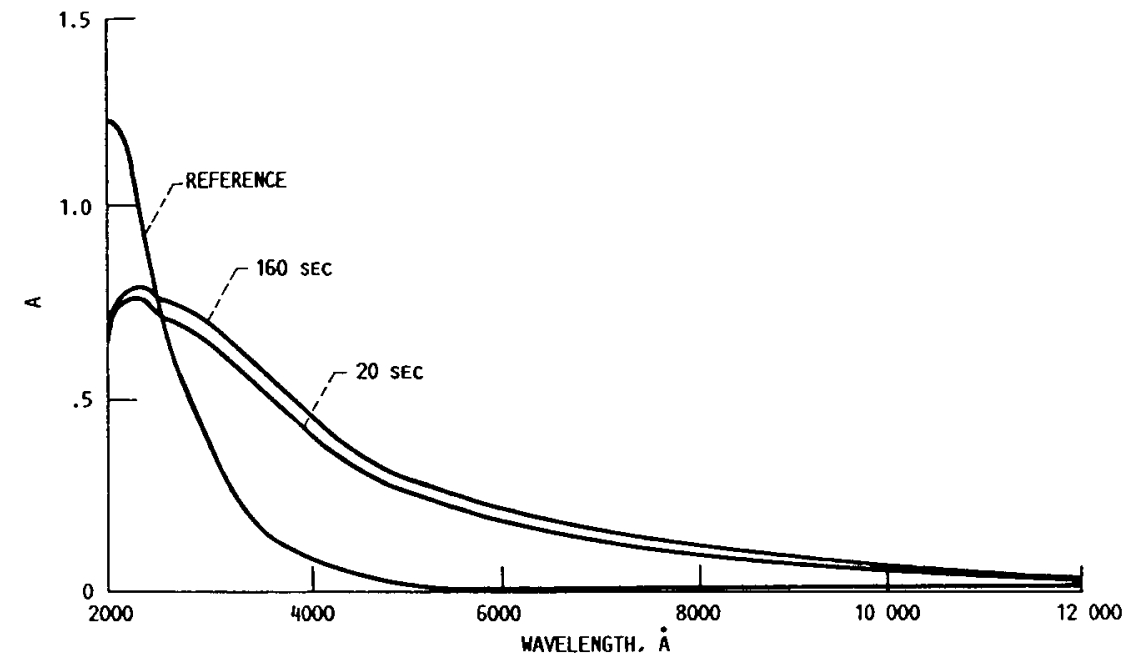

FIGURE 2. - ABSORBANCE A VERSUS MAVELENGTH FOR a - C:H FILAS ON QUARTZ, ANMEALED AT $500^{\circ} \mathrm{C}$ FOR 20 AND $160 \mathrm{SEC}$. AND A REFERENCE.

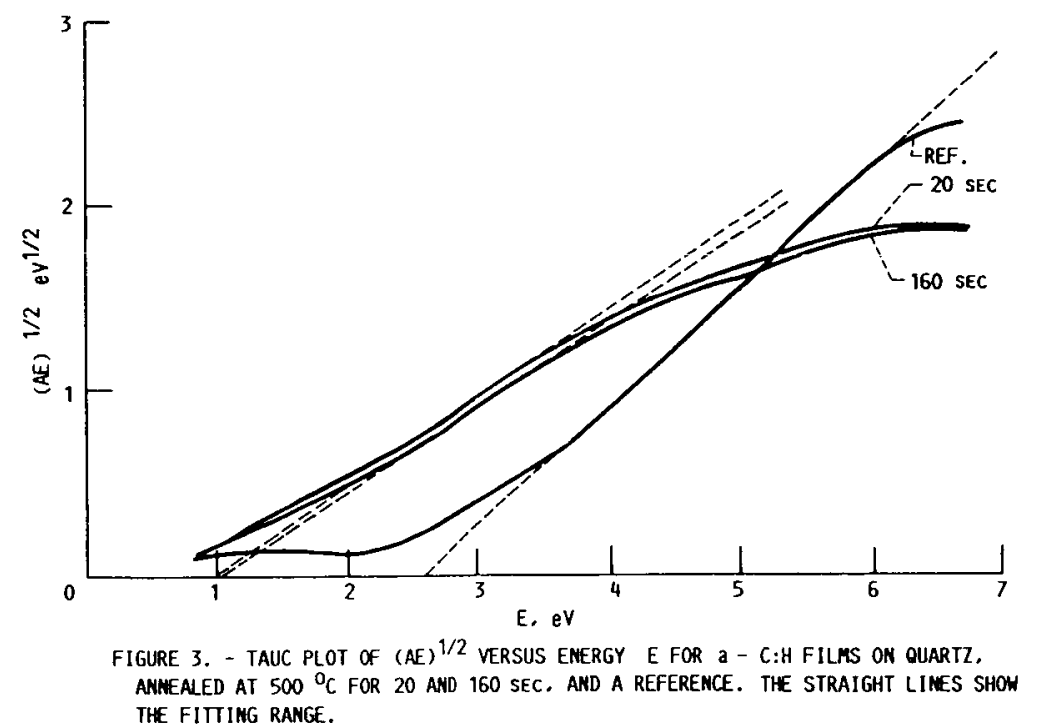




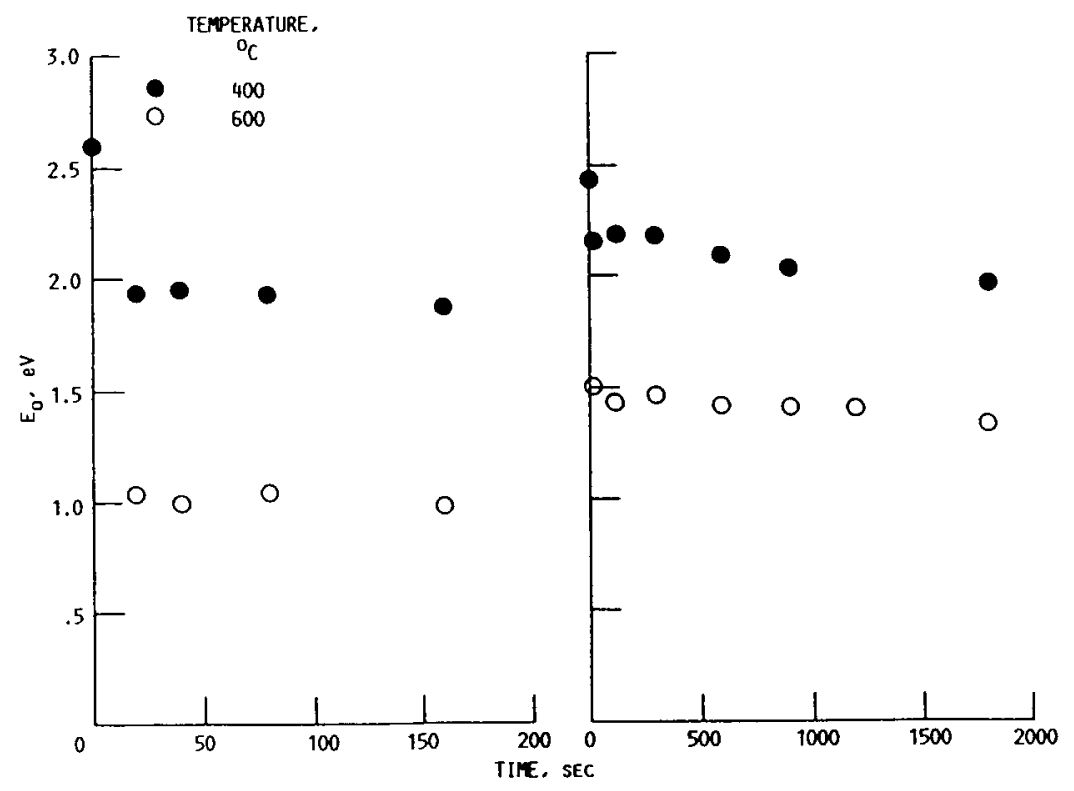

(A) SHORT TIME AMHEALS.

(B) LONG TIRE ANREALS.

FIGURE 4. - OPIICAL EMERGY GAP E ANMEALED AT TNO TEMPERATURES.

Ellipsometric measurements were done on $\mathrm{a}-\mathrm{C}: \mathrm{H}$ films on S1 substrates. $\psi$ and $\Delta$ results were inverted using a three-phase model [11] to obtain the refractive indices $n$, extinction coefficients $k$ (at each wavelength), and the thickness. We found that the three phase model, especially for processed samples, gives excellent fits. The results for $K$ were analyzed in the form of $(\alpha E)^{1 / 2}$ versus $E$, as shown in Fig. 5 . Here $\alpha$ is the absorption coefficient, $\alpha=4 \pi K / \lambda$. The optical bandgaps found were markedly smaller than for the films on quartz substrates. The slope of the $(\alpha E)^{1 / 2}$ versus $E$ graph, also denoted $B$, is called the density of states parameter $[8,10]$. The values obtained for $B, E_{0}$, and the thicknesses are given in Table I. Results of the refractive index are shown in Fig. 6.

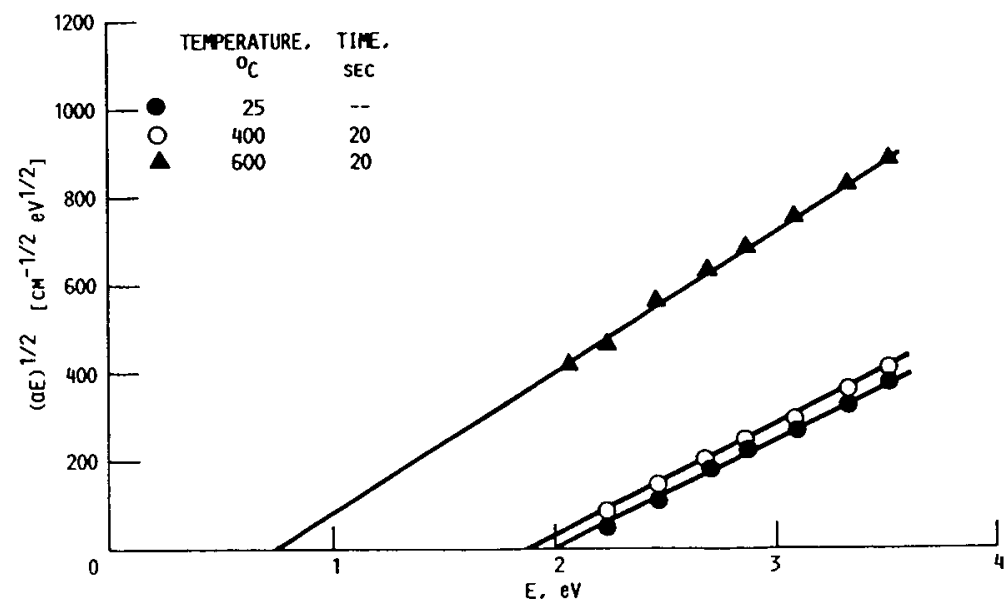

FIGURE 5. - TANC PLOT Of (aE) ${ }^{1 / 2}$ VERSUS ENERGY E FOR a - C:H FILMS ON $S_{1}$. ANHEALED FOR 20 SEC AT $400^{\circ} \mathrm{C}$ AND $600^{\circ} \mathrm{C}$. AND A REFEREMCE. 


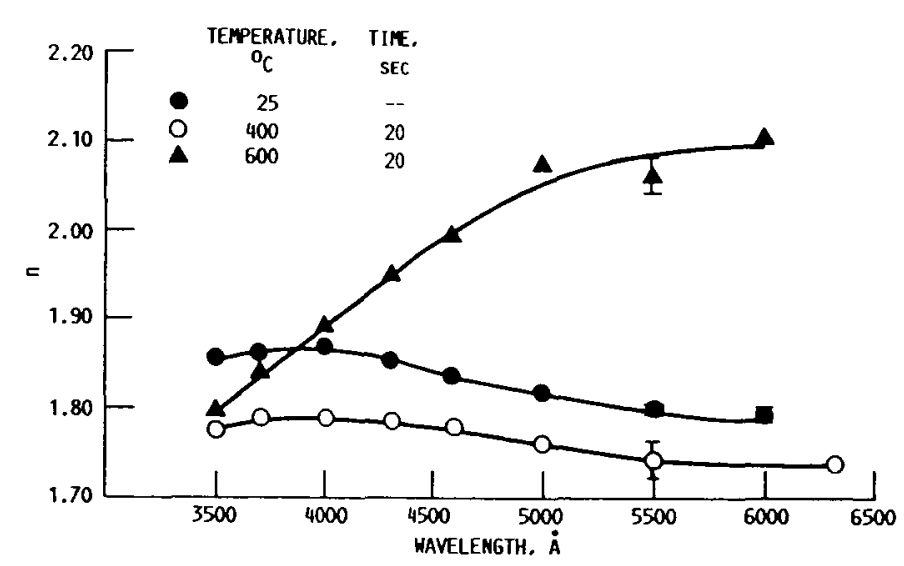

FIGURE 6. - REFRACIIVE INDEX $\cap$ VERSUS WAVELENGIH FOR a - C:H FILNS ON SI. AMHEALED FOR 20 SEC AI $400^{\circ} \mathrm{C}$ AND $600^{\circ} \mathrm{C}$. AND A REFEREMCE.

A comparison was performed for samples processed with the film pointing upward or downward. We found that for films pointing up, the absorbance peak at $\sim 2000$ \& was markedly reduced versus the films pointing down, especially for long processing times and high temperatures. (Up to 40 percent reduction for $300 \mathrm{sec}$ at $500{ }^{\circ} \mathrm{C}$.) However, the optical bandgap $E_{0}$ was unchanged to within better than 1 percent. We attribute this large reduction in absorbance to a reduction in $\mathrm{f} i \mathrm{~lm}$ thickness. This fact is probably due to small amounts of oxygen present in the processing gas.

\section{DISCUSSION}

The main result obtained in this work is shown in Fig. 4. The main part of the reduction in the optical bandgap is obtained at short times. This fact can also be deduced by the result obtained by laser annealing [12], when processing time is much shorter than those reported here. However, there is a definite increase in absorption (Fig. 2) and decrease in bandgap (Fig. 4) for increasing processing times of order $10^{2}-10^{3} \mathrm{sec}$. The mechanism involved should be a two-step process. There is known to be a two-stage pyralysis of organic material into graphite [13] for temperatures in this range, namely carbonization and polymerization. Carbonization stage includes loss of volatile matter, which we identify with hydrogen loss in this case [14]. This stage occurs in the temperature range 400 to $600{ }^{\circ} \mathrm{C}$ in a-C:H. Polymerization stage includes the formation of graphitic crysta1lites or sheets. If we assume that the polymerization is a diffusion dependent process with relatively long time constant (of order $10^{3} \mathrm{sec}$ ), then we can deduce that the two processes of carbonization and polymerization occur simultaneously in our films. The abrupt decrease of the bandgap versus time at very short processing time is due to the hydrogen loss, while the subsequent decrease in $E_{0}$ is due to increase in cluster size [13]. More work is required to check the validity of this assumption.

The absorbance $A$ versus wavelength $\lambda$ plot at $600{ }^{\circ} \mathrm{C}$ ( $\mathrm{Fig} .2$ ) shows a decrease in peak height and a shift in the peak position. The shift has been observed earlier [14] and shows changes in the carbon bonding. The decrease in peak height is attributed mostly to loss of material in this case, as it is opposite to the results obtained at $400{ }^{\circ} \mathrm{C}$ by us and to published results [14].

A large decrease in bandgap has been observed when quartz substrates have been replaced by Si (Figs. 4 and 5), although the samples were prepared in the same deposition run. The main reason is the fact that $S i$ is a conductor with resistivity of order $0.01 \Omega \mathrm{cm}$, while quartz is an insulator. As a result, the plasma above the substrates, and subsequently the films, are different in each case. 
The ellipsometric results on films processed for $20 \mathrm{sec}$ partially reproduce the results obtained earlier [15] for $1 \mathrm{hr}$ annealed films. For the $600{ }^{\circ} \mathrm{C} \mathrm{film}$, we found increased refractive indices at low energies and increased density of states parameter $B$ versus the reference film (Table I). However, the $400{ }^{\circ} \mathrm{C} f 11 \mathrm{~m}$ shows a decrease in the refractive index and slight increase in thickness, while the parameter $B$ stays the same. This fact may be explained by mechanical changes in the film as the volatile gas is expelled, and voids are left behind.

TABLE I. - ELLIPSOMETRIC RESULTS OF a-C:H

FILMS ANNEALED FOR 20 SEC

\begin{tabular}{|c|c|c|c|}
\hline $\mathrm{T},{ }^{\circ} \mathrm{C}$ & $\mathrm{B}, \mathrm{cm}^{-1 / 2} \mathrm{ev}^{-1 / 2}$ & $\mathrm{E}_{\mathrm{O}}, \mathrm{eV}$ & $\mathrm{d}, \AA$ \\
\hline Reference & 250 & 2.02 & 2790 \\
400 & 250 & 1.90 & 3110 \\
600 & 318 & 0.75 & 1690 \\
\hline
\end{tabular}

\section{CONCLUSIONS}

An abrupt decrease of the optical bandgap $E_{0}$ has been observed for short time (of order $20 \mathrm{sec}$ ) rapid thermal processing. A small, additional decrease of $E_{0}$ is observed for times of order $10^{3} \mathrm{sec}$. A two-stage mechanism is proposed to explain the result.

\section{ACKNOWLEDGMENT}

The authors would like to thank Mr. N.S. Shoemaker for technical assistance with the measurements.

\section{REFERENCES}

1. J.S. Williams and S.J. Pearton, in Energy Beam-Solid Interactions and Transient Thermal Processing/1984, D.K. Biegelson, G.A. Rozgonyi and C.V. Shank, eds., Materials Research Society, Pittsburgh, PA, p. 427 (1985).

2. N.M. Johnson, in Energy Beam-Solid Interactions and Transient Thermal Processing/7984, D.K. Biegelson, G.A. Rozgonyi and C.V. Shank, eds., Materials Research Society, Pittsburgh, PA, p. 265 (1985).

3. S. Yasuami, Y. Saito, and A. Hojo, Jpn. J. Appl. Phys. 23, 379 (1984).

4. T.J. Faith and C.P. Wu, App 1. Phys. Lett. 45, $470(1984)$.

5. Z.A. Weinberg, D.R. Young, J.A. Calise, S.A. Cohen, J.C. Deluca, and V.R. Deline, App 1. Phys. Lett. 45, 1204 (1984).

6. J.D. Lamb and J.A. Woollam, J. Appl. Phys. 57, 5420 (1985).

7. J.E. Oh, J.D. Lamb, P.G. Snyder, J.A. Woollam, and D.C. Liu, Solid State Electronics 29 , 933 (1986).

8. S.A. Alterovitz, J.D. Warner, D.C. Liu, and J.J. Pouch, Jr1. Electrochem. Soc. 133, 2339 (1986).

9. Model 2106 made by Process Products Corp.

10. N.F. Mott and E.A. Davis, Electronic Processes in Non-Crystalline Materials, 2nd ed., Clarendon Press, 0xford, p. 289 (1979).

11. S.A. Alterovitz, G.H. Bu-Abbud, J.A. Woollam, and D.C. Liu, J. Appl. Phys., 54, 1559 (1983).

12. S. Prawer, R. Kalish, and M. Adel, Appl. Phys. Lett. 48, 1585 (1986).

13. J. Robertson, Adv. Phys. 35, 317 (1986).

14. J.C. Angus, P. Koidl, and S. Domitz, Plasma Deposited Thin Films, J. Mort and F. Jansen, eds., CRC Press, Boca Raton, p. 89 (1986).

15. F.W. Smith, J. Appi. Phys. 55, 764 (1984). 


\begin{tabular}{|c|c|c|c|}
\hline $\begin{array}{l}\text { 1. Report No. } \\
\text { NASA TM-89859 }\end{array}$ & 2. Government Accession No. & \multicolumn{2}{|c|}{ 3. Recipient's Catalog No. } \\
\hline \multicolumn{2}{|l|}{ 4. Title and Subtitle } & \multicolumn{2}{|l|}{ 5. Report Date } \\
\hline \multicolumn{2}{|c|}{$\begin{array}{l}\text { Rapid Thermal Annealing of Amorphous Hydrogenated } \\
\text { Carbon }(a-C: H) \text { Films }\end{array}$} & \multicolumn{2}{|c|}{$\begin{array}{l}\text { 6. Performing Organization Code } \\
506-44-2 C\end{array}$} \\
\hline \multirow{2}{*}{\multicolumn{2}{|c|}{$\begin{array}{l}\text { 7. Author(s) } \\
\text { Samue1 A. Alterovitz, John J. Pouch; and } \\
\text { Joseph D. Warner }\end{array}$}} & \multicolumn{2}{|c|}{$\begin{array}{l}\text { 8. Performing Organization Report No. } \\
\text { E-3519 }\end{array}$} \\
\hline & & \multicolumn{2}{|l|}{ 10. Work Unit No. } \\
\hline \multicolumn{2}{|c|}{$\begin{array}{l}\text { 9. Performing Organization Name and Address } \\
\text { National Aeronautics and Space Administration } \\
\text { Lewis Research Center } \\
\text { Cleveland, Ohio } 44135\end{array}$} & \multicolumn{2}{|c|}{ 11. Contract or Grant No. } \\
\hline \multirow{2}{*}{\multicolumn{2}{|c|}{$\begin{array}{l}\text { 12. Sponsoring Agency Name and Address } \\
\text { Nationa } 1 \text { Aeronautics and Space Administration } \\
\text { Washington, D.C. } 20546\end{array}$}} & \multicolumn{2}{|c|}{$\begin{array}{l}\text { 13. Type of Report and Period Covered } \\
\text { Technical Memorandum }\end{array}$} \\
\hline & & \multicolumn{2}{|c|}{ 14. Sponsoring Agency Code } \\
\hline \multicolumn{4}{|c|}{$\begin{array}{l}\text { 15. Supplementary Notes } \\
\text { Prepared for the } 1987 \text { Spring Meeting of the Materials Research Society, Anaheim, } \\
\text { California, Apri1 21-25, } 1987 \text {. }\end{array}$} \\
\hline \multicolumn{4}{|c|}{$\begin{array}{l}\text { Amorphous hydrogenated carbon (a-C:H) films were deposited on silicon and quartz } \\
\text { substrates by a } 30 \mathrm{kHz} \text { plasma discharge technique using methane. Rapid thermal } \\
\text { processing of the films was accomplished in nitrogen gas using tungsten halogen } \\
\text { light. The rapid thermal processing was done at several fixed temperatures (up } \\
\text { to } 600{ }^{\circ} \mathrm{C} \text { ), as a function of time (up to } 1800 \mathrm{sec} \text { ). The films were characterized } \\
\text { by optical absorption and by ellipsometry in the near UV and the visible. The } \\
\text { bandgap, estimated from extrapolation of the } 1 \text { inear part of a Tauc plot, } \\
\text { decreases both with the annealing temperature and the annealing time, with the } \\
\text { temperature dependence being the dominating factor. The density of states param- } \\
\text { eter increases up to } 25 \text { percent and the refractive index changes up to } 20 \text { percent } \\
\text { with temperature increase. Possible explanations of the mechanisms involved in } \\
\text { these processes are discussed. }\end{array}$} \\
\hline $\begin{array}{l}\text { 17. Key Words (Suggested by Author(s)) } \\
\text { Rapid thermal processing } \\
\text { Amorphous carbon films }\end{array}$ & $\mid \begin{array}{r}\text { 18. Distributi } \\
\text { Unc las } \\
\text { STAR }\end{array}$ & $\begin{array}{l}\text { d }- \text { unlimite } \\
\text { ry } 76\end{array}$ & \\
\hline $\begin{array}{l}\text { 19. Security Classif. (of this report) } \\
\text { Unc lass if i ed }\end{array}$ & $\begin{array}{l}\text { 20. Security Classif. (of this page) } \\
\text { Unc lass if Ied }\end{array}$ & $\begin{array}{c}\text { 21. No. of pages } \\
7\end{array}$ & $\begin{array}{r}\text { 22. Price* } \\
\mathrm{AO} 2\end{array}$ \\
\hline
\end{tabular}

"For sale by the National Technical Information Service, Springfield, Virginia 22161 